\title{
Étude immunoélectrophorétique du sérum de zébu Gobra au Sénégal Possibilité de variations saisonnières qualitatives
}

\author{
par J. ROUMEGOUX et M. P. DOUTRE (*)
}

\begin{abstract}
RESUME
Après avoir fourni une description des techniques employées : immunoélectrophorèse et gel-filtration sur colonne de Sephadex G 200., les auteurs présentent l'inage immunoélectrophorétique du sérum de zébu Gobra, en précısant la nature des 15 lignes de précıpitation obtenues. L'étude se termine par des considérations sur la possibilité d'éventuelles variations saisonnières des protéines sériques. Les résultats ne laissent apparaître aucune différence d'ordre qualitatif entre des prélèvements recue1llis en fin de saison humide et ceux récoltés en fin de saison sèche. En particulier, les trois immunoglobulınes: IgG, IgM et IgA se retrouvent sur toutes les images immunoélectrophorétiques de l'ensemble des sérums utilisés au cours du présent travail. Par contre, sur le plan quantitatıf, on note une diminution significative du taux des protéines totales pour les sérums obtenus en fin de saison sèche. Cette dernière observation est confırmée par une étude électrophorétique qui doit faire l'objet d'une publication prochaine.
\end{abstract}

En 1965, au Tchad, PROVOST, BORREDON et QUEVAL mettent en évidence une hypogammaglobulinémie essentielle chez des zébus d'Afrique centrale (15).

A la suite de ces observations, une étude a été effectuée au Sénégal sur le zébu Gobra.

Ce travail a été réalisé en deux temps :

1. Qualitativement : en utilisant conjointement la chromatographie sur colonne de Sephadex G 200 et l'immunoélectrophorèse.

2. Quantitativement: par l'analyse électrophorétique sur acétate de cellulose.

Ce dernier travail fera l'objet d'une note séparée. Seuls les résultats obtenus lors de

(*) Institut d'Elevage et de Médecine Vétérinaire des Pays Tropicaux, Maisons-Alfort. - Laboratoire national de l'Elevage et de Recherches vétérinaires, Dakar-Hann (Sénégal). l'étude qualitative ont été rapportés dans la présente publication.

En 1968, I.S.WARD-COX, en Afrique du Sud, montre l'apparition progressive des immunoglobulines chez le veau nouveau-né (19). Le même auteur, en 1969, révèle par immunoélectrophorèse une agammaglobulinémie chez quelques bovins (20).

En 1969, W. PENHALE et G. CHRISTIE comparent au cours d'une étude quantitative le taux des immunoglobulines sériques chez les bovins d'Europe (races: Ayrshire, Frisonne, Jersey, Guernesey et Shorthorn) et chez le zébu. Les résultats obtenus montrent une augmentation appréciable de l'IgG et de l'IgM chez le bétail d'origine africaine (1) (12).

A notre connaissance, il n'existe pas de travaux donnant un diagramme complet de déter-

(1) Nous utilisons la nomenclature officielle. 
mination des différentes lignes de précipitation constituant l'image immunoélectrophorétique d'un sérum de bovin. Nous avons done tenté dans un premier temps d'identifier les différents arcs afin d'éviter par la suite toute erreur d'interprétation. Dans un deuxième temps, nous avons entrepris une étude comparative de sérums récoltés, dans le Ferlo, en fin de saison des pluies et en fin de saison sèche, afin de rechercher d'éventuelles variations liées à l'état d'entretien des animaux.

\section{MATERIEL ET METHODES}

\section{A. Récolte des sérums objet de l'étude}

Le sang est prélevé aseptiquement à la jugulaire. Après coagulation, le sérum est centrifugé et réparti dans des ampoules à sceller à raison de $3 \mathrm{ml}$ par ampoule.

Les sérums ainsi conditionnés sont stockés à $-20^{\circ} \mathrm{C}$.

\section{B. Préparation des anti-sérums}

Plusieurs techniques ont été utilisées avec des résultats différents :

a) Ane

Une émulsion est préparée avec les constituants suivants :

— Sérum de zébu . . . . $20 \mathrm{ml}$

— P.B.S. . . . . . . . . . $10 \mathrm{ml}$

- Adjuvant complet de Freud . . $20 \mathrm{ml}$

Tout d'abord, $20 \mathrm{ml}$ de cette émulsion sont injectés par voie intramusculaire profonde en répartissant la dose en 4 points différents (encolure et cuisses). Ensuite, 25 jours après, débute une série de 6 injections intraveineuses d'antigène. $\mathrm{Ce}$ dernier est préparé de la façon suivante :

- $3 \mathrm{ml}$ de sérum;

- $47 \mathrm{ml}$ de PBS.

On ajoute $23 \mathrm{ml}$ de bicarbonate de sodium $\mathrm{N}$, puis goutte à goutte, en agitant $50 \mathrm{ml}$ d'une solution à 10 p. 100 d'alun de potassium (AlK $\left(\mathrm{SO}_{4}\right) 2,12 \mathrm{H}_{2} \mathrm{O}$ ). La suspension est abandonnée à $4^{\circ} \mathrm{C}$ pendant une nuit, puis centrifugée à froid $30 \mathrm{mn}$ à $3.000 \mathrm{t} / \mathrm{mn}$. Le précipité est enfin remis en suspension dans $80 \mathrm{ml}$ de PBS.
Les injections sont faites au rythme de 2 par semaine :

- $1^{\mathrm{re}}$ semaine : $0,5 \mathrm{ml}$ et $1 \mathrm{ml}$;

- $2^{\mathrm{e}}$ semaine : $2 \mathrm{ml}$ et $4 \mathrm{ml}$;

$-3^{\mathrm{r}}$ semaine : $8 \mathrm{ml}$ et $16 \mathrm{ml}$.

Le premier prélèvement de sang est effectué 10 jours après la dernière injection. Pour pallier aux accidents anaphylactiques éventuels, chaque injection d'antigène est précédée d'un traitement au phénergan (I.M.).

En principe, l'animal continue à produire des anticorps pendant plusieurs mois. Cette méthode permet d'obtenir un sérum d'âne antizébu qui révèle parfaitement les immunoglobulines.

\section{b) Lapins}

\section{Première méthode}

Une technique identique d'immunisation a été utilisée.

- Première injection: quantité pour deux lapins :

— Sérum de zébus . . . . . . $0,5 \mathrm{ml}$

- P.B.S. . . . . . . . . $1,5 \mathrm{ml}$

- Adjuvant complet de Freud . . 2,0 ml

On injecte $0,1 \mathrm{ml}$ de l'émulsion sous chaque coussinet plantaire. Le reste est inoculé dans chaque cuisse par voie intramusculaire.

- Injections ultérieures: 25 jours plus tard, par voie intraveineuse de la préparation antigénique suivante :

- 0,3 ml de sérum;

- 4,7 $\mathrm{ml}$ de P.B.S.

On ajoute $2,3 \mathrm{ml}$ de bicarbonate de soude $\mathrm{N}$, puis goutte à goutte en agitant $5 \mathrm{ml}$ d'une solution à 10 p. 100 d'alun de potassium. La solution est abandonnée à $4^{\circ} \mathrm{C}$ pendant une nuit, puis centrifugée. Le précipité est repris dans $8 \mathrm{ml}$ de P.B.S.

Injections renouvelées 2 fois par semaine suivant le rythme :

- $1^{\text {re }}$ semaine : $0,05 \mathrm{ml}$ et $0,1 \mathrm{ml}$;

- $2^{\mathrm{e}}$ semaine : $0,15 \mathrm{ml}$ et $0,3 \mathrm{ml}$;

- $3^{\mathrm{e}}$ semaine : $0,4 \mathrm{ml}$ et $0,8 \mathrm{ml}$.

Le sang des lapins est récolté 15 jours après la dernière injection. 
Cette méthode couramment utilisée pour l'obtention de sérums lapin anti-humains n'a donné que des résultats médiocres dans la préparation de sérum anti-zébu. Il semble que les mauvais résultats obtenus soient dus à une trop faible quantité de sérum de zébu dans la constitution du mélange antigénique.

\section{Deuxième méthode}

Le meilleur sérum anti-bovin total a été produit par injections par voie intraveineuse de sérum de zébu non traité à des lapins.

Rythme des injections :

7 injections de $2 \mathrm{ml}$ de sérum de zébus à 2 jours d'intervalle dans la veine marginale de l'oreille. La saignée est pratiquée 15 jours après la dernière injection. Chaque lapin fournit en moyenne $50 \mathrm{ml}$ de sérum anti.

De cette façon, un excellent sérum anti donnant 15 lignes de précipitation a été obtenu.

\section{Remarque}

L'utilisation d'un sérum de zébu normal pour l'hyperimmunisation des lapins ne permet pas d'obtenir une bonne ligne de précipitation de l'IgM.

C'est la raison pour laquelle ont été utilisés soit des sérums d'animaux trypanosomés riches en IgM, soit un sérum de zébu hyperimmunisé au préalable au moyen d'une culture de Salmonella typhimurium formolée. L'injection de l'antigène 0 des salmonelles provoque en effet une forte élévation de 1'IgM.

Pour ce faire, le processus suivant a été adopté : 2 inoculations par semaine par voie intraveineuse à doses progressivement croissantes : $5 \mathrm{ml}, 10,15,20, \ldots 75,80$ pendant 2 mois (récolte du sérum 15 jours après la dernière injection).

Le sérum ainsi obtenu, inoculé à des lapins, a permis de préparer un sérum lapin antizébu total révélant particulièrement bien l'IgM.

\section{Troisième méthode}

L'hyperimmunisation de lapin au moyen des fractions I (IgM) et IV (IgG) obtenues par chromatographie sur colonne de Sephadex G 200 a permis de préparer des immunsérums qui, après épuisement par un sérum de fœtus de veau, révèlent exclusivement l'lgG et $\operatorname{l'IgM}\left({ }^{2}\right)$.

(2) Industrie Biologie Française, S.A., 92-Genneviltiers.

\section{Géloses-tampons}

\section{a) Immuno-électrophorèse}

Les gels sont préparés soit avec lc Special Agar Noble (Difco) soit avec l'agarose. Le Special Agar Noble (Difco) est constitué par un mélange d'agarose et d'agaropectine.

L'agaropectine porte des groupements acides sulfoniques responsables d'une partie des propriétés du gel d'agar. Ainsi l'IgG, l'IgA et l'IgM, soumis à un fort courant d'électroendosmose, migrent vers le pôle négatif. L'agarose, au contraire, n'ayant pas ces groupements acides, possède une inertie chimique relative et donne lieu à un faible courant d'électroendosmose au cours de l'électrophorèse, ce qui peut présenter un avantage notamment dans l'étude des immunoglobulines (9). Si l'agarose donne des lignes de précipitation plus nettes, plus nombreuses et mieux réparties, la présence du puits de départ dans la concavité de l'arc de l'IgM peut être gênante pour l'étude particulière de cette globuline.

De plus, la multiplication des arcs est aussi un facteur de complication. En fait, le choix de l'un ou l'autre des deux gels sera fonction des fractions auxquelles on s'intéresse.

Le tampon utilisé, qui a donné les meilleurs résultats, répond à la composition suivante :

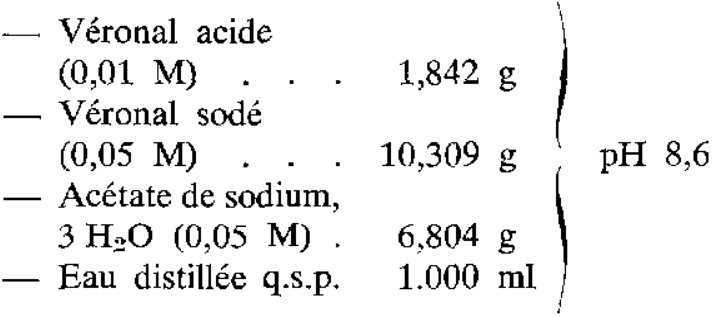

Le gel, support de l'immuno-électrophorèse, est préparé dans les proportions suivantes:

- Agar noble . . . . . . . $1 \mathrm{~g}$

- Tampon . . . . . . . . $25 \mathrm{ml}$

— Eau distillée . . . . . . . $75 \mathrm{ml}$

Ces proportions sont les mêmes si on utilise l'agarose. Le gel, ainsi préparé, est réparti en tubes de $20 \mathrm{ml}$, conservés à $+4^{\circ} \mathrm{C}$.

\section{b) Chromatographie}

Elle est rêalisée sur colonne de Sephadex G $200\left({ }^{3}\right)$.

L'éluant est une solution tampon dont la composition est la suivante :

(3) Pharmacia Fine Chemicals, Uppsala, Suède. 


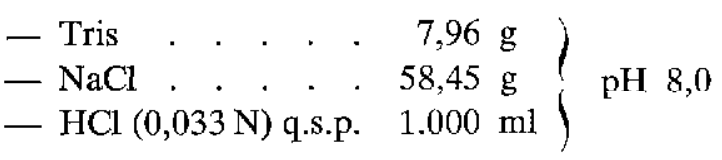

\section{Techniques}

\section{a) Immunoélectrophorèse}

Ont été utilisées la microméthode sur lames de $2,5 \times 7,5 \mathrm{~cm}$ et la macrométhode sur lames de $16 \times 4 \mathrm{~cm}$ (21).

L'appareillage Gelman pour immunoélectrophorèse a été employé tout au long du présent travail (générateur de courant continu donnant une tension de 0 à $500 \mathrm{~V}$ ).

Les différents stades de la méthode correspondent à la description classique : dégraissage des lames, coulage de la gélose, découpage à l'emporte-pièce des puits de départ et de la gouttière des immun-sérums (portoir de 6 lames), dépôt du sérum à étudier. L'électrophorèse est menée sous $220 \mathrm{~V}$ pendant $60 \mathrm{mn}$ pour la microméthode et $140 \mathrm{mn}$ pour la macrométhode. On procède ensuite à l'application de l'immunsérum. L'incubation se fait en chambre humide pendant 24 à 36 h. Après lavage ( $24 \mathrm{~h}$ en sérum physiologique, $1 \mathrm{~h}$ en eau distillée) et séchage (à l'étuve à $37^{\circ} \mathrm{C}$ ), la coloration est réalisée au noir-amide en solution méthanolacétique pendant $5 \mathrm{mn}$. L'excès de colorant est éliminé par une solution de rinçage. Les lames sont enfin lavées à l'eau courante et séchées.

Solution de rinçage :

-- Alcool méthylique . . . . 5 vol.

- Acide acétique . . . . 1 vol.

- Eau distillée. . . . . . 5 vol.

Solution de coloration:

- Noir amide . . . . . . $6 \mathrm{~g}$

- Solution de rinçage . . . . $1.000 \mathrm{ml}$

b) Chromatographie

Conduite selon les indications de HOGMAN et KILLANDER (10).

Le fractionnement des sérums de zébu a été effectué sur colonne de Sephadex G 200 (gel de dextrane).

Le gel de Sephadex est placé dans une colonne de $800 \mathrm{~mm}$ de hauteur et $30 \mathrm{~mm}$ de diamètre. Après s'être assuré de la verticalité rigoureuse de la colonne, le sérum est déposé uniformément à la partie supérieure du gel à raison de $3 \mathrm{ml}$.
L'éluant est envoyé sur la colonne par une pompe électrique.

A la sortie de la colonne, un absorptiomètre à UV $(280 \mathrm{~m} \mu)$, couplé à un enregistreur, permet de détecter les différentes fractions qui sont ensuite réparties en tubes de $5 \mathrm{ml}$ par le collecteur de fractions Beckman muni d'un compteur de gouttes.

A la fin de la chromatographie, l'enregistreur a inscrit sur bande de papier une courbe à 3 pics (voir schéma I) qui matérialise la séparation des différentes fractions sériques. Ainsi, dans l'exemple choisi, la courbe montre que la totalité du sérum a filtré entre les tubes 17 et 61 du collecteur. Dans cet intervalle, les tubes ont été regroupés en 7 fractions :

- $1^{\text {re }}$ fraction: tubes 17 à 19;

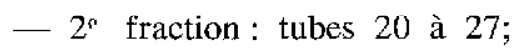

- $3^{\mathrm{e}}$ fraction : tubes 27 à 36 ;

- 4c fraction: tubes 37 à 44 ;

- $5^{\mathrm{e}}$ fraction: tubes 45 à 48 ;

- $6^{\mathrm{r}}$ fraction: tubes 49 à 52 ;

- $7^{\mathrm{e}}$ fraction: tubes 53 à 61 .

Chaque fraction est ensuite dialysée contre de l'eau distillée à $+4^{\circ} \mathrm{C}$, pour éliminer les sels du tampon, puis lyophilisée.

La dialyse et la concentration des fractions obtenues par la chromatographie peuvent être réalisées plus rapidement en un seul temps par la technique de dialyse sous vide (schéma 2). En $12 \mathrm{~h}$. à $+4^{\circ} \mathrm{C}$, la concentration est environ de 10 fois.

\section{IMAGE \\ IMMUNO-ELECTROPHORETIQUE DU SERUM DE ZEBU GOBRA}

L'immuno-électrophorèse d'un sérum de zébu Gobra réalisée dans les conditions décrites ci-dessus a permis d'obtenir 15 lignes de précipitation.

\section{Identification des différents arcs}

\section{a) Fractionnement d'un sérum}

La filtration sur gel de dextrane (Sephadex G 200) sépare les protéines sériques selon leur taille, leur vitesse de migration dans le gel étant pour partie directement proportionnelle à la grosseur de la molécule. 


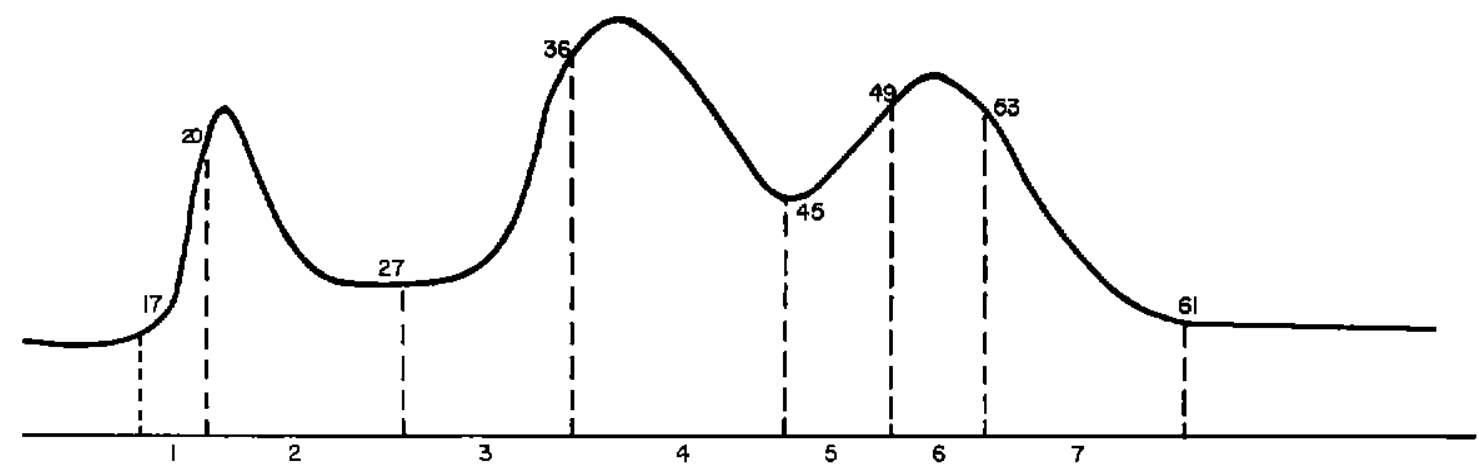

Schema 1 - Courbe de fractionnement d'un serum de zébu sur Sephadex G.200.

Chaque fraction obtenue par chromatographie est comparée sur la même préparation avec le sérum total. Quelques lignes parfaitement visibles sur les lames sont difficilement rendues par les photographies.
La photographie de l'image immunoélectrophorétique de chacune des 7 fractions est reproduite dans les clichés $\mathrm{n}^{\circ} 1$ à 7 avec indication des différents constituants dont la position a pu être figurée.

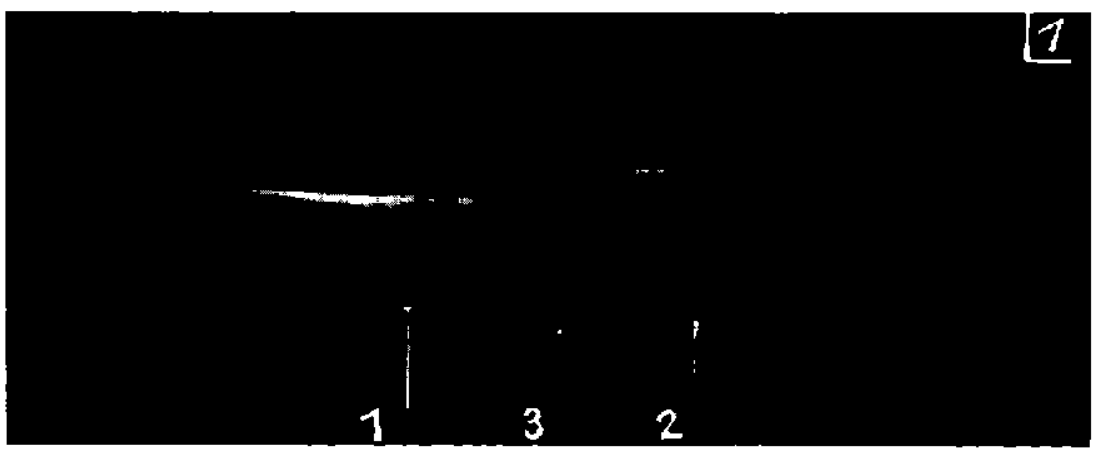

\section{Photo 1}

1. $\operatorname{IgM}$

2. $\alpha$ 2-macroglobuline

3. $\beta$-lipoprotéine

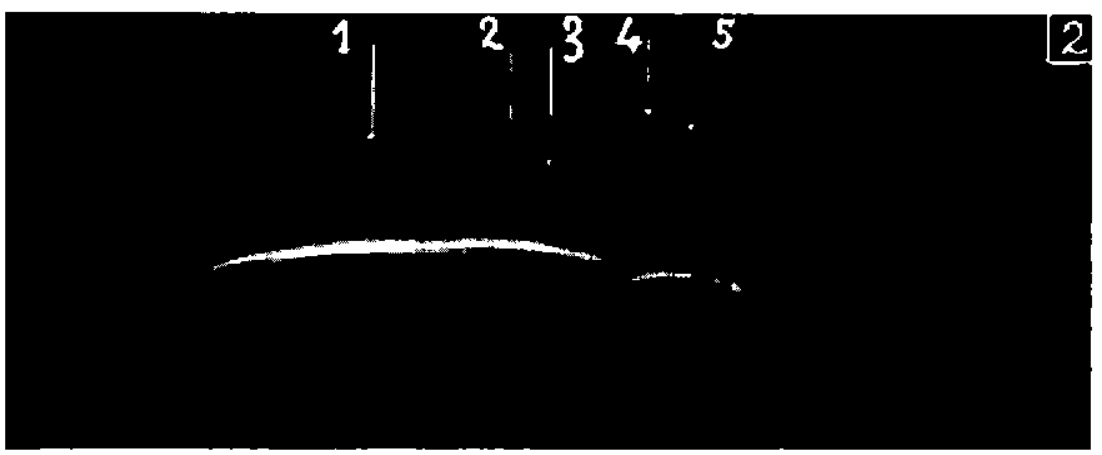

\section{Photo 2}

1. IgM

2. 2 macroglobuline

3. Transférine

4. $\beta$-lipoprotéine

5. Céruloplasmine 


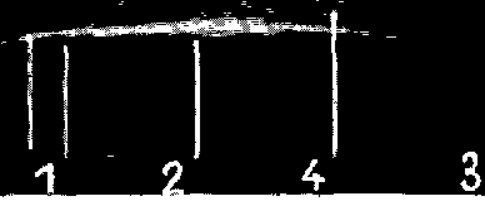

Photo 3

1. IgG lente

IgG rapide

2. $\operatorname{Ig} A$

3. 1 A globuline

4. $\alpha 2$ séromucoïde

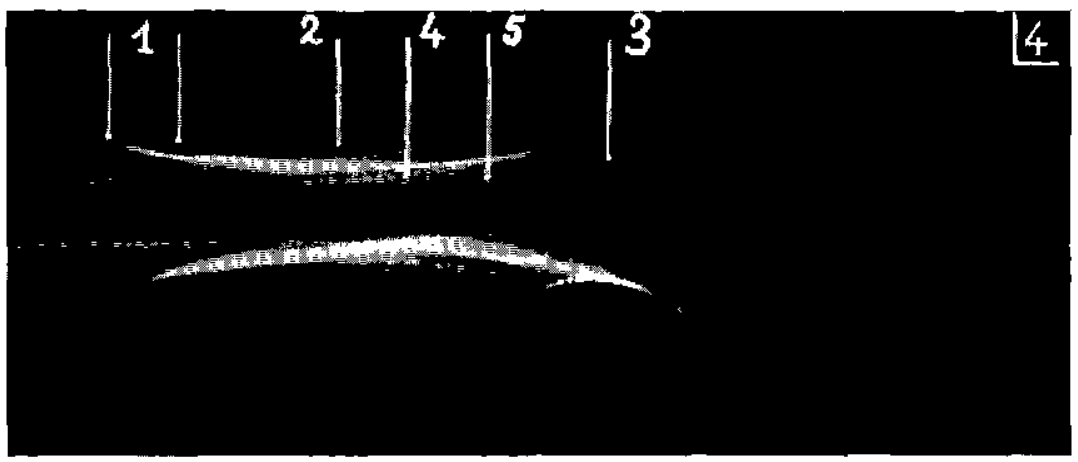

Photo 4

1. $\mathrm{IgG}$ lente

IgG rapide

2. IgA

3. $\beta 1$ A globuline

4. Haptoglobine

5. Transférine

Photo 5

1. IgG lente IgG rapide

2. Transférine

3. $\beta 1 \mathrm{~A}$ globuline

4. Haptoglobine

5. $\alpha 1$ glycoprotéine

6. Albumine

Photo 6

1. Transférine

2. « 1 glycoprotéine

3. $\alpha 1$ séromucoide

4. Albumine 


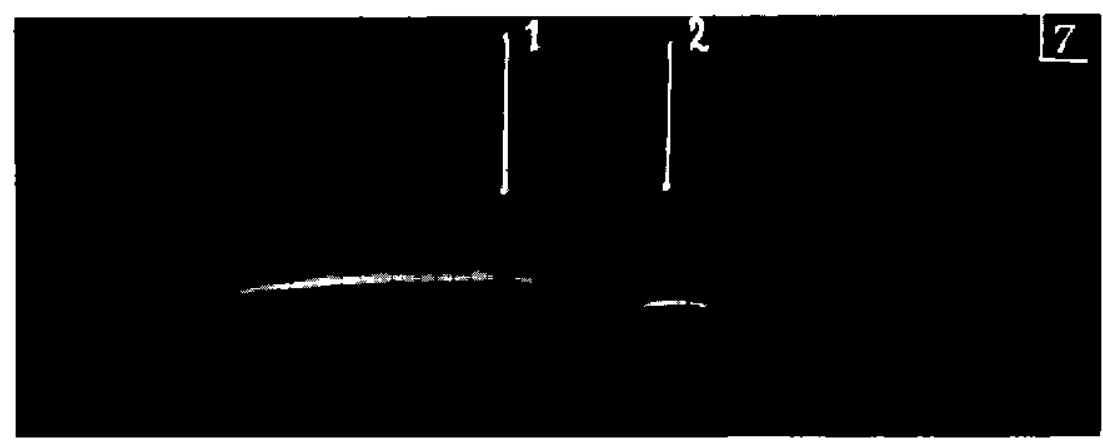

Photo 7

1. Transférine

2. $\alpha 1$ séromucoïde

\section{b) Préparation de l'IgM}

La préparation de l'IgM pure par filtration sur Sephadex implique l'élimination de l' $\alpha 2$ macroglobuline ainsi que de la $\beta$-lipoprotéine (10).

\section{- Précipitation de la lipoprotéine :}

A $10 \mathrm{ml}$ d'un sérum normal, on ajoute $0,4 \mathrm{ml}$ d'un solution de sulfate de dextrane à 10 p. 100 , puis $1 \mathrm{ml}$ d'une solution de $\mathrm{Ca} \mathrm{Cl}_{2}, \mathbf{M}$. On agite et après $15 \mathrm{mn}$ de repos, on centrifuge $10 \mathrm{mn}$ à $6.000 \mathrm{~g}$. On recueille le surnageant. L'excès de $\mathrm{Ca} \mathrm{Cl}_{2}$ est éliminé par dialyse contre de l'eau distillée.

\section{- Précipitation des euglobulines :}

On ajuste le volume de ce surnageant à $200 \mathrm{ml}$ à l'aide d'une solution d'acide borique à $7,5 \mathrm{~g} /$ litre.
On centrifuge pendant $10 \mathrm{mn}$ à $2.000 \mathrm{~g}$, après une demi-heure de repos.

Le précipité est lavé 2 fois avec la solution d'acide borique puis il est repris dans 3 à $4 \mathrm{ml}$ du tampon Tris-H Cl-Na Cl de $\mathrm{pH}=8,0$.

La filtration est enfin réalisée sur la colonne de Sephadex G 200.

\section{c) Autres immunoglobulines}

Les autres immunoglobulines ont été préparées par épuisements successifs des sérums de zébus par un sérum de lapin hyperimmunisé avec un sérum de fœtus de veau dépourvu d'IgG et d'IgM. La photo 8 montre l'image immunoélectrophorétique d'un sérum d’embryon de veau à terme manifestement dépourvu d'IgG et d'IgM (19).

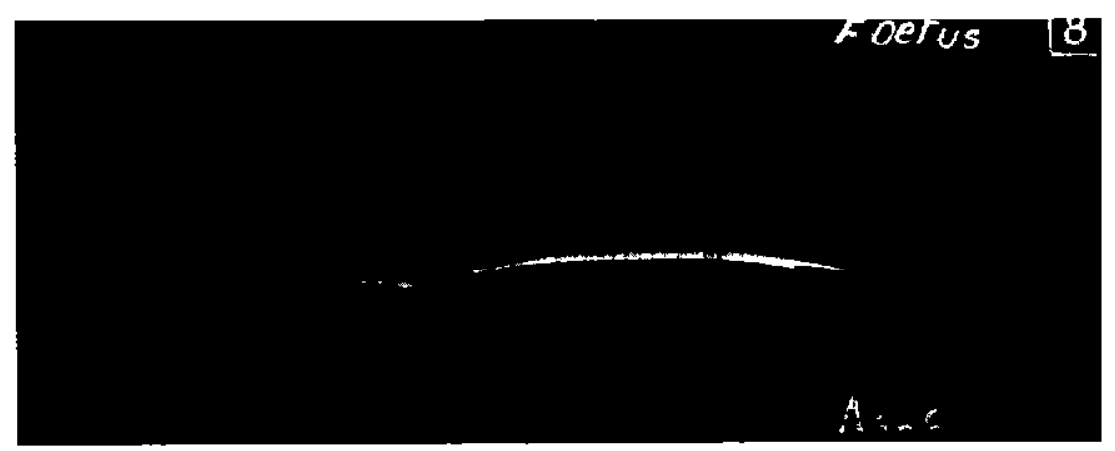

Photo 8

Image immuno-

électrophorétique d'un sérum d'embryon de veau.

\section{d) Colorations spécifiques}

Pour la mise en évidence des lipoprotéines, on peut utiliser des colorants spécifiques: Oil Red O ou Soudan B.

Des colorations spéciales, comme celle dé- crite par URIEL (18) pour mettre en évidence l'action oxydative de la céruloplasmine permettent de préciser certaines lignes de précipitation.

Seules les colorations spécifiques des lipoprotéines qui n'offrent pas de difficulté majeure ont été réalisées dans le présent travail. 


\section{Lecture d'une lame d'immunoélectrophorèse}

Avant d'envisager la lecture d'une lame, quatre critères sont à retenir :

- Un antigène est d'autant plus abondant que sa ligne de précipitation est plus proche de la gouttière des immunsérums.

- L'abondance d'un antigène peut être évaluée d'après l'intensité de son précipité, à condition que le rapport antigène-anticorps ait une valeur bien déterminée. Lorsque l'antigène se trouve en grande quantité, l'excès peut dissoudre le précipité.
- Un antigène est d'autant plus abondant que sa ligne de précipitation est moins courbe.

- La ligne de précipitation est floue du côté opposé au réactif en excès. Pour avoir des lignes nettes, il convient d'ajuster les concentrations respectives d'antisérum et de sérum à étudier.

Il est à noter que l'albumine apparaît rarement sur les préparations. En réalité, au cours du développement, elle est la première à se former, mais elle disparaît ensuite, le précipité étant dissout par l'excès d'antigène. Des photographies prises en cours d'incubation, sans coloration, montrent très nettement la ligne de précipitation de l'albumine (photo 9).

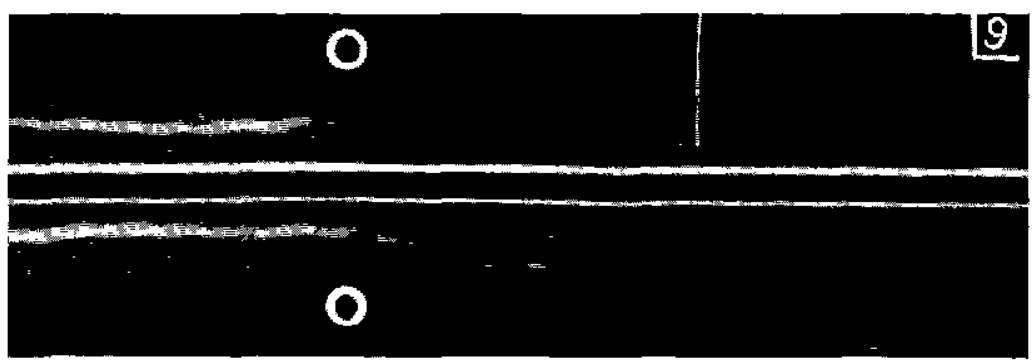

Photo 9

Photo réaliscée en cours d'incubation, sans coloration, l'arc correspondant à l'albumine est nettement visible.

En conclusion, l'application des différentes techniques décrites ci-dessus ont donc permis d'identifier 15 lignes (photo 10).

A noter que les lignes n'apparaissent géné- ralement pas sur une même lame, les concentrations respectives de sérum et d'antisérum doivent être ajustées en fonction des globulines à étudier.

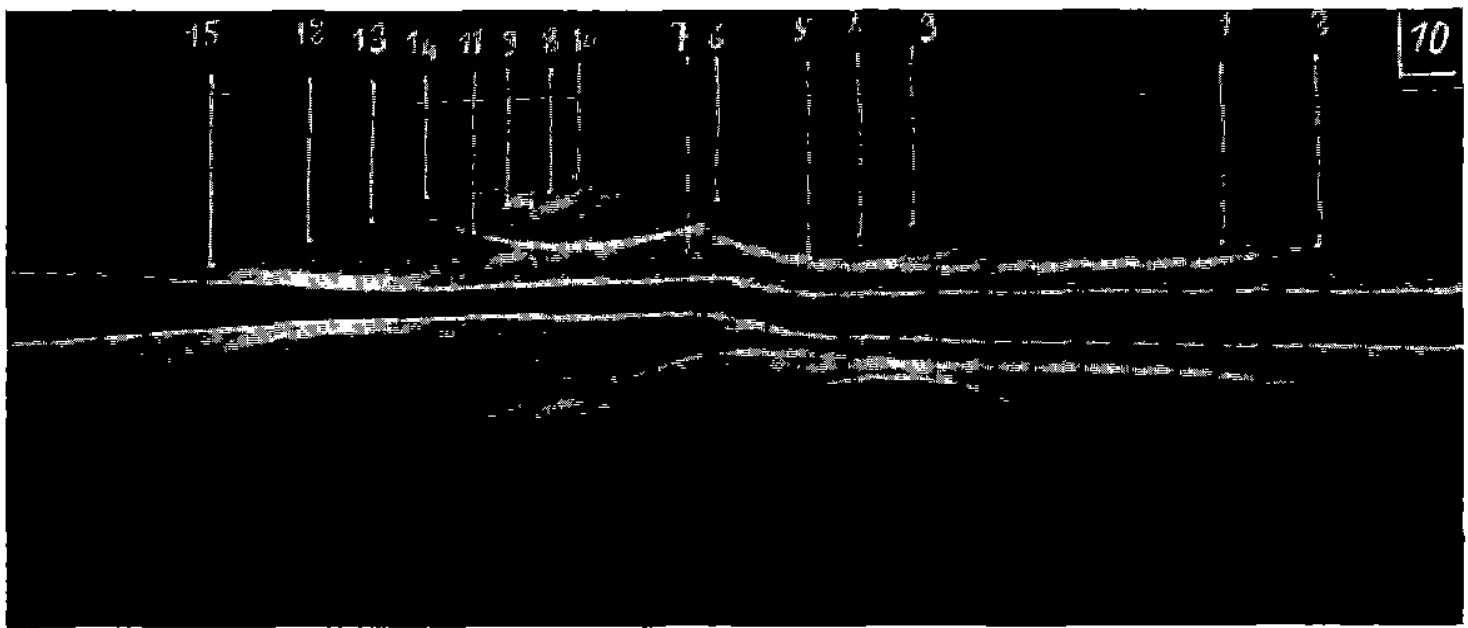

Photo 10

1. IgG lente

2. IgG rapide

3. IgM
4. IgA

5. Transférine

6. $\beta$-lipoprotéine
7. Haptoglobine

8. a 2-macroglobuln

9. Céruloplasmine
10. o 2-lipoprotéine

11. $\beta 1$ A globuline

12. a 1-glycoprotéine
13. a. 1 séromucoïde

14. a $1 \mathrm{X}$-glycoprotéine (?)

15. Alburnine 


\section{ETUDE DES VARIATIONS \\ SAISONNIERES QUALITATIVES \\ DES PROTEINES SERIQUES \\ DU ZEBU GOBRA}

1. 115 sérums ont été prélevés au mois de novembre 1969 , en fin de saison des pluies, sur des zébus du Ferlo (Dara). Les animaux, cliniquement sains, étaient en parfait état d'entretien.

Du point de vue qualitatif, les images immunoélectrophorétiques se sont révélćes être parfaitement identiques pour tous les sérums analysés. Dans tous les cas, les immunoglobulines
IgG, IgA et IgM sont parfaitement visibles, comme sur la photo 11 par exemple.

Sur le plan quantitatif, autant que l'on puisse en juger en immunoélectrophorèse, il semble qu'il $y$ ait quelques légères variations individuelles principalement au niveau des immunoglobulines. Par exemple on voit que le sérum de la photo 11 est moins riche en IgM. Il faut préciser que le même immunsérum a été utilisé pour toute la série. De plus, les quantités de sérum et d'immunsérum appliquées au moyen de micro-pipettes graduées étaient connues et identiques. Les conditions de travail étant rigoureusement définies et reproduites, il est donc parfaitement possible de faire des comparaisons d'ordre quantitatif.

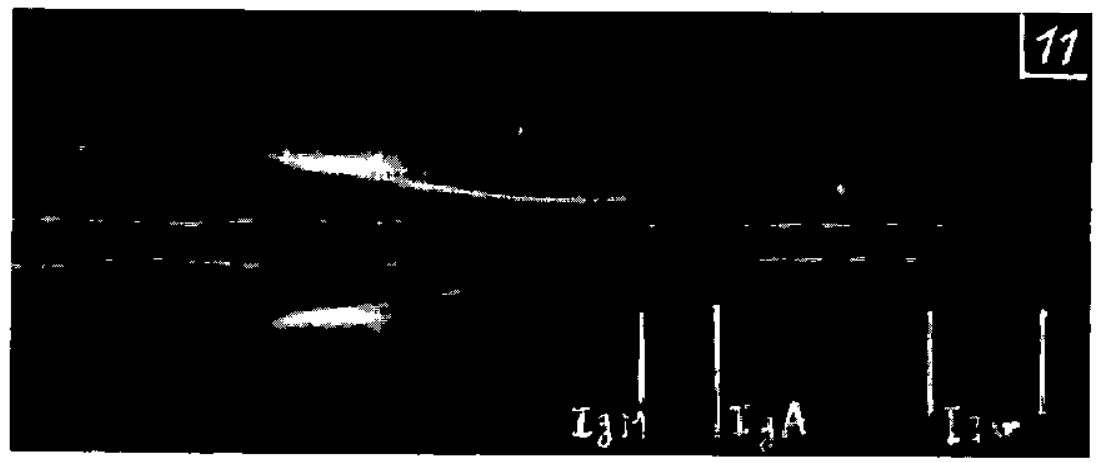

Photo 11

2. Au mois de mai 1970,72 sérums ont été recueillis sur des zébus de la même région (forage de Tatki). A cette époque de l'année, les animaux présentent un amaigrissement saisonnier maximal du fait des conditions d'alimentation de semaine en semaine plus difficiles.

L'analyse immunoélectrophorétique de ces sérums a été effectuée avec le même immunsérum de lapin. Pour chaque lame, la comparai- son a été faite avec un même sérum de zébu prélevé en fin de saison des pluies. Les résultats montrent qu'aucune des immunoglobulines n'a disparu mais que, par contre, toutes les fractions apparaissent moins abondantes. De façon constante, la ligne de précipitation de l'IgG est moins marquée et plus courte que sur le sérum témoin (ainsi qu'on peut le voir sur la photo 12). De même, l'IgM est beaucoup moins visible. Pour toutes les autres fractions, les arcs

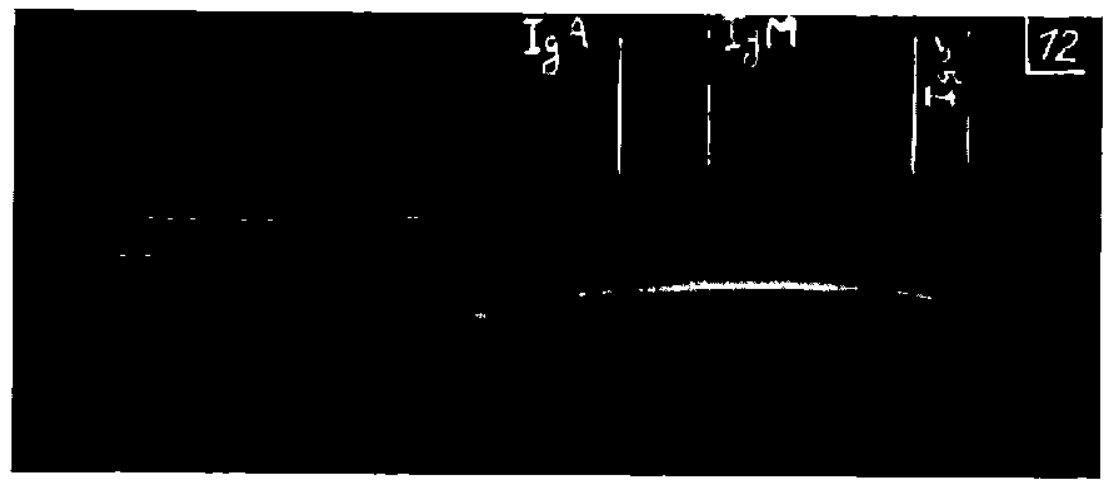


de précipitation sont plus courbes et moins nets, ce qui indique une diminution du taux de la protéine en cause.

L'étude quantitative menée conjointement par la méthode d'électrophorèse sur acétate de ccllulose a permis de confirmer et de chiffrer ce résultat.

En conclusion, le sérum des bovins, en fin de saison sèche, présente un abaissement significatif des protéines totales, chacun des consti- tuants étant intéressé. Par contre, en aucun cas, la disparition complète d'une quelconque fraction n'a été observée, immunoglobulines comprises.

\section{Remerciements}

Nous tenons à remercier le Professeur MASSEYEFF et ses collaborateurs de la Faculté de Médecine de Dakar pour l'aide technique qu'ils nous ont apportée tout au long de la présente étude.

\title{
SUMMARY
}

\section{Immunoelectrophoretic study of Gobra zebu serum in Senegal.} Possibility of qualitative seasonal variation

\begin{abstract}
In a first step, the authors describe the technics and methods which will be used all along the present work: immunoelectrophoresis and gel filtration chromatography on Sephadex G 200. An immunoelectrophoretic pattern of Gobra zebu serum is given with the nomenclature of each of the 15 precipitation lines obtained. The study is achieved with considerations on any possible seasonal variation of serum proteins. The results show no qualitative difference between samples collected at the end of the rainy season and those gathered at the end of the dry season. In particular, the three immunoglobulins are present on the immunoelectrophoretic patterns of all the sera used along the present study. On the other hand, on quantitative basis, a significant decrease of total proteins rate is demonstrated for the sera collected at the end of the dry season. This last observation is confirmed by an electrophoresis study which will be published separately in a further paper.
\end{abstract}

\section{RESUMEN}

\section{Estudio inmunoelectroforetico del suero de cebú Gobra en Senegal.} Posibilidad de variaciones cualitativas de estación

Los autores describen las técnicas utilizadas: inmunoelectroforesis y gelosa-filtración sobre columna de Sephadex G 200. Luego, presentan la imagen inmunoelectroforetica del suero de cebú Gobra, al precisar la esencia de las 15 líneas de precipitación obtenidas. Se acaba el estudio por consideraciones sobre la posibilidad de eventuales variaciones de estación de las proteinas sericas. Según los resultados, no existe ningun diferencia de orden cualitativo entre las muestras recogidas al fin de la estación húmeda y las recogidas al fin de la estación seca. Particularmente, las tres inmunoglobulinas: IgG, IgM e IgA se encuentran en todas las imagenes inmunoelectroforeticas del conjunto de los sueros utilizados durante este estudio. En cambio, desde el punto de vista cuantitativo, se nota una disminución significativa de la tasa de las proteinas totales en los sueros obtenidos al fin de la estación seca. Se cónfirma la última observación por un estudio electroforetico que se publicara proximamente.

\section{BIBLIOGRAPHIE}

1. BIBERFELD (G.), «Distribution of antibody within $19 \mathrm{~S}$ and $7 \mathrm{~S}$ immunoglobulins following infection with Mycoplasma pneumoniae », J. Immunol., 1968, 100 (2): 338-47.

2. GÓTZ (H.) et HEINEBRODT (A.), « Biochemical and immunoelectrophoretic analysis of cattle serum », Zentbl. Vet. Med., 1969, 16 A : 691-702.

3. HERMANS (J.), « Les globulines sériques du système gamma. Leur nature et leur pathologie », Paris, Masson, 1961.
4. HIRSCHFELD (J.), «The use of immunoelectrophoresis in the analysis of normal sera and in studies of the inheritance of certain serum proteins ", Sci. Tools, 1961, 8 (3) : 17-24.

5. HIRSCHFELD (J.), «Immunoelectrophoresis procedure and application to the study of groupspecific variations in sera ", Sci. Tools, 1960, 7 (2) : 18-25.

6. JONAS (W. E.), « Determination of sheep antiSalmonella typhimurium immunoglobulin class by 
antiglobulin testing ", Res. vet. Sci, 1969, 10 (4): 311-20.

7. JONAS (W. E.), «Immunoelectrophoretic analysis of sheep serum using guinea-pig antisera to particulate antigens treated with sheep ant1-serum $»$, Res. v'et. Sci., 1969, 10 (5) : 397-404.

8. Mc EWAN (A.D.), EISCHER (E.W.) et SEIMAN (I. E.), "Observations on the immunoglobulin levels of neonatal calves and their relationship to disease $n$, J. comp. Path., 1970, 80 (2): 259.65.

9. MASSEYEFF (R.) et GOMBERT (J.), « Comparasson entre l'agar et l'agarose comme support de l'analyse immunoélectrophorétique du sérum», Bull. Mém. Fac. mixte Méd. Pharm. Dakar, 1965, 13 : 100-02.

10. MASSEYEFF (R.), GOMBERT (J.) et JOSSELIN (J.), "Méthode de préparation de la beta 2-macroglobuline du sérum humain ", Immunochemistry, 1965, 2 : 177-80.

11. "Nomenclature for human imnunoglobulins », Bull. Org. Mond. Santé, 1964, 30 : 447-50.

12. PENHALE (W. J.) et CHRISTIE (G.), "Quantitative studies on bovine immunoglobulins. I. Adult plasma and colostrum levels \%, Res. ret. Sci., 1969, 10: 493-501.

13. PENHALE (W. J.) et Collab., «Quantitative studies on bovine immunoglobulins. - II, Plasma immunoglobulin levels in market calves and their relationship to neonatal infection », Brst. vet. J., 1970, 126: 30-37.

14. «Production of antibody against purified human gamma-globulin in rabbits, goats, sheep and horses », Immunology, 1966, 10: 271.
15. PROVOST (A.), BORREDON (C.) et QUEVAL (R.), "Une hypogammaglobulinémie essentielle des bovins d'Afrique Centrale, cause d'erreur dans les enquêtes sérologiques ».Rev. Elè. Méd. vét. Pays trop, 1965, 18 (4) : 385.93.

16. SCHULTZE (H. E.) et HEREMANS (J. F.), "Molecular biology of human proteins ", Amsterdam, London, New York, Elsevier Publ. Co., 1966, I.

17. TRAININ (Z.), «Immunoelectrophoretic analysis of serum from a leukemic cow $», A m$. J. vet Res., 1969,30 (8) : 1475.77.

18. URIEL (J.), « Etude de l'activité enzymatique de la céruloplasmine du sérum humain après électrophorèse et immunoélectrophorèse en gélose », Bull. Soc. Chim. biol., 1957, 39 (suppl. I) : 105.

19. WARD-COX (I. S.), «A note on gamma-globulin content of the serum of new born calves $», J . S$. Afr. vet. med. Ass., 1968, 39 (3), 51-52.

20. WARD-COX (I. S.), « Two instances of bovine agammaglobulinaemia as revealed by immunoelectrophoresıs », J.S. Afr. vet. med. Ass., 1969, 40 (3) : 337.

21. WARD-COX (I. S.), «Incorporation of a macroslide in the micro technique of immunoelectrophoresis ", J.S. Afr. vet. med. Ass., 1969, 40 (I) : 91-92.

22. WEIR (D. M.), * Handbook of experımental immunology », Oxford, Edinburg, Blackwell Scientifıc Publication, 1967.

23. WILLIAMS (C. A.) et CHASE (M.W.), «Methods in immunology and immunochemistry \&, New York, London, Academic Press, 1967, I et II. 